Gut, 1961, 2, 175

Methods and techniques

\title{
The motility of the pelvic colon 1 Motility in normals and in patients with asymptomatic duodenal ulcer
}

\author{
A. M. CONNELL \\ From the Department of Gastroenterology, Central Middlesex Hospital, \\ and the Research Department, St. Mark's Hospital, London
}

The study of the motility of the alimentary tract has lagged behind the study of its secretory activity, largely due to difficulties of technique. For many years, radiology has contributed extensively to our knowledge but has obvious limitations. It is now generally agreed that only some form of continuous manometry is suitable for accurate quantitative work. Early studies using large balloons and relatively insensitive manometers are suspect because of the physiological and mechanical artefacts produced by large distending balloons (Quigley and Brody, 1950) although some information about colonic motility has been obtained by this method (Adler, Atkinson, and Ivy, 1941; Spriggs, Code, Bargen, Curtiss, and Hightower, 1951).

More recently, however, the development of transducers, which are small enough to be swallowed, open-ended tubes, and miniature balloons has made it possible to record the unstimulated activity of the alimentary tract. These methods have been applied extensively and successfully to the study of oesophageal motility but very few studies of intestinal motility have been made. A detailed study of the colonic motility of children using open-ended tubes has been presented by Davidson, Sleisenger, Almy, and Levine (1956). This study presents an analysis of the unstimulated motility of the sigmoid colon recorded under resting physiological conditions in adult normal subjects and patients with duodenal ulceration. These later were studied because standard textbooks (Bockus, 1944; Avery Jones and Gummer, 1960) indicate that a number of patients with duodenal ulceration have symptoms of colonic type, and so far no study of colonic motility has been attempted in these patients. It should be emphazised that these patients were symptom free at the time although an ulcer was present.
METHODS

TECHNIQUE OF RECORDING PRESSURE Intraluminal pressures have been recorded using miniature balloons $(7 \mathrm{~mm}$. in diameter $\times 10 \mathrm{~mm}$. length) (Atkinson, Edwards, Honour, and Rowlands, 1957) connected by fine polyethylene tubing to a metal capsule optical manometer of high sensitivity (Rowlands, Honour, Edwards, and Corbett, 1953). The total volume of the recording system is about $1 \mathrm{c.cm}$. and the change of volume with variation in pressure is very small. Simultaneous recordings from a miniature balloon and an open-ended tube in the same segment of gut are identical except when the balloon is compressed by the muscular wall as at the cardia. Under these conditions the pressures indicated by the balloon are greater than would be recorded from an open-ended tube at the same site (Edwards and Rowlands, 1960). In the sigmoid, however, records from a miniature balloon and open-ended tube are usually identical (Fig. 1). A model of the conditions in the colon was prepared by placing an open-ended tube and a miniature balloon in the same position inside a large soft rubber balloon. The pressure inside the large balloon was varied over a wide range and resulted in similar pressures in the two recording systems. The pressure recorded by the open-ended tube was $13 \%$ higher than that recorded by the miniature balloon, but when the latter was directly compressed by the wall of the large balloon it recorded pressures up to $33 \%$ higher than the open-ended tube under similar conditions. In addition records from miniature balloons have been compared with those from radio pills, recording from exactly the same position in the gut. An exact qualitative comparison has been obtained although there are some minor quantitative differences (Connell and Rowlands, 1960). Some of the earlier studies reported in this paper were made with open-ended tubes but miniature balloons were preferred subsequently. The open-ended tubes did not consistently give reliable results due to blocking with faeces, even if a slow stream of air under high pressure was bled continuously through them in an effort to keep them patent. 


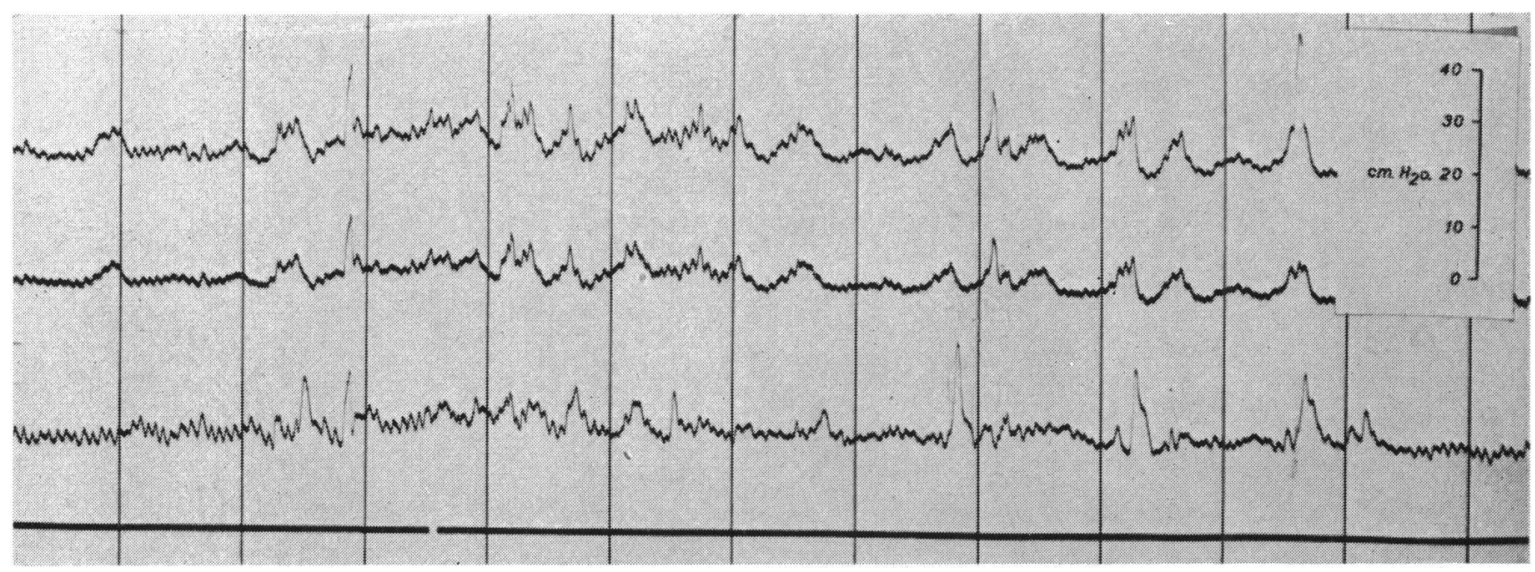

FIG. 1. Comparison of the records produced by a miniature balloon and an open-ended tube in the same segment of bowel. Top tracing: Miniature balloon. Middle tracing: open-ended tube in same segment. Lower tracing: recording from a different segment of bowel. Verticals $=1$ minute intervals. Calibration in $10 \mathrm{~cm}$. water steps.

In most of the studies, three balloons were used and tied to tubes at distances of $5 \mathrm{~cm}$. from each other.

Sleeves of radio-opaque tubing were interposed between the balloons and a sleeve of fine semi-rigid polyethylene tubing was placed over the connecting tubes to simplify insertion into the colon. The recording tube was connected to the optical manometer and the system adjusted for temperature and pressure so that, under resting conditions, the air in the balloon was at atmospheric pressure when at body temperature. Under these conditions the walls of the balloon were lax. No air was inserted into the balloons.

PATIENTS AND PROCEDURE Colonic motility has been studied in 32 subjects, most of whom were hospital inpatients. Fourteen had radiological and subsequent operative evidence of chronic duodenal ulceration but had no ulcer symptoms during the period of study. The remaining 18 subjects were either normal or suffering from general medical or minor surgical complaints (pilonidal sinus, post-infective fistula-in-ano, intermittent claudication, bleeding haemorrhoids, etc). None had suffered from any prolonged bouts of abdominal pain or any prolonged disorder of bowel function. All were symptom free at the times of study.

In addition, records have been obtained on nine different occasions from two other patients who complained of abdominal pain and in whom repeated investigations over a period of years had been negative.

All studies were made with the patient relaxing on a couch in a quiet room. The subjects were encouraged to read light literature. No food was allowed for two hours before the beginning of the study.

Without any prior preparation of the patient, a small bore Lloyd Davies sigmoidoscope was passed to beyond the rectosigmoid angle without distending the colon with air. The tubes and recording balloons, still attached to the manometer, were passed into the colon through the sigmoidoscope which was then withdrawn. As it is not consistently possible to insinuate the tubes for more than a few centimetres along the colon without tedious and time-consuming manoeuvres, the recording tips were placed routinely at 25,20 , and $15 \mathrm{~cm}$. from the anus. The position of the tube has been checked radiologically in several patients using an image intensifier and it has been shown that its position does not alter appreciably even in studies lasting several hours. After placing the tube in the colon half an hour was allowed to elapse before the recording began and this was continued for periods of up to five hours.

It is essential to record the respiratory and body movement at the same time as colonic motility. This was done by using a piece of gas mask tubing as a stethograph around the upper abdomen and attached to a capsule of the manometer. Without the use of a stethograph no reliable information can be obtained about the faster components of colonic activity.

ANALYSIS OF RECORDS Preliminary observation of the records indicated that when colonic activity was phasic the cycle was nearly always less than 30 minutes in duration although very occasionally periods of inactivity lasting more than one hour were seen. In two patients in whom recordings were made over a period of several hours, analyses were made over consecutive half-hour periods. These indicated that with the exception of the increase of activity associated with eating, the activity of these half-hour periods remained relatively constant (Fig. 2). Eighteen records were analysed over half-hour periods and subsequently over one-hour periods but no significant differences were found in the mean results of the two groups (Table I). Half hour periods of analysis therefore are adequate for studies comparing groups of patients.

Each record was carefully checked against the stethograph and all variations which appeared to represent 


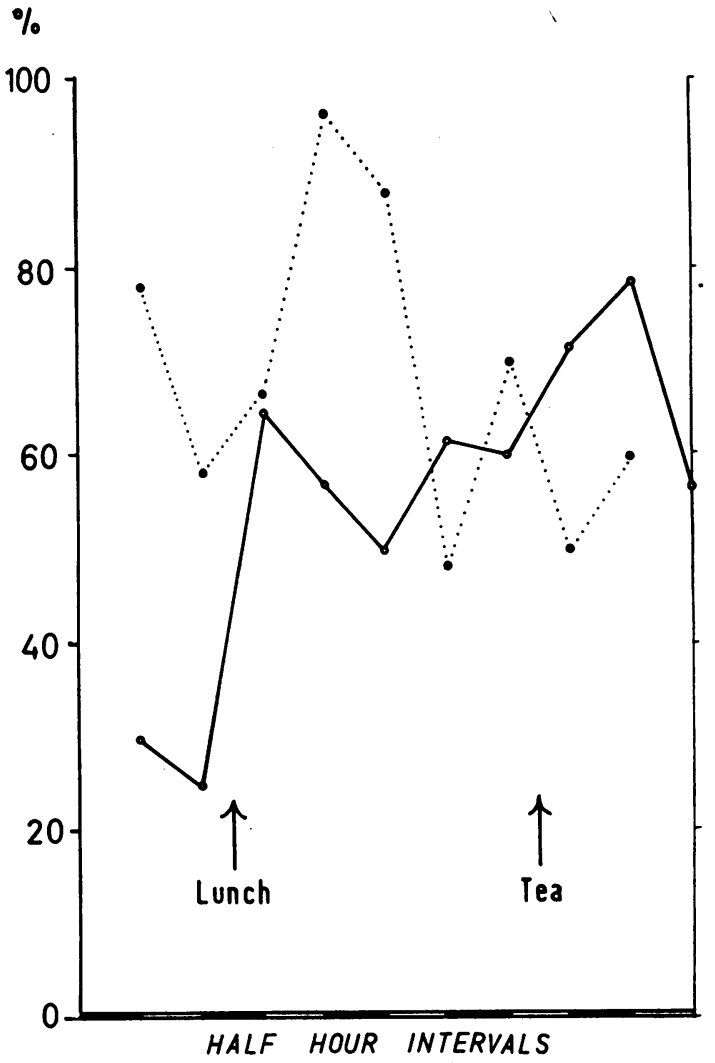

FIG. 2. The percentage duration of activity of two subjects estimated each half hour on records lasting several hours. cardiovascular, respiratory, or somatic movement were excluded from further consideration. The following parameters were measured over a period of 30 minutes in each record:

The duration of colonic activity was measured and expressed as a percentage of the time of analysis. For this purpose activity was defined as any rise in basal pressure which was not accounted for by cardiovascular, respiratory, or somatic movement. For example, in Fig. 3 the base line alterations of the upper two traces would be considered as activity whereas in the bottom trace the only base line alterations can be accounted for as respiratory swings. However, prolonged slow base line alterations lasting many minutes and not amounting to more than 3 or $4 \mathrm{~cm}$. of water pressure have not been considered as activity for the purposes of this analysis.

An arbitary distinction has been made between pressure waves occurring at a frequency of five per minute or more and those at less than five per minute. The amplitude of the slow waves (frequency less than five per minute) was measured and the mean amplitude in each record calculated. In addition, the proportion of the slow waves which represent pressures of more than $20 \mathrm{~cm}$. water was estimated. Where the waves occurred in rhythmic sequence the frequency of this phasic activity was recorded.

An assessment of colonic activity is given by the product of the total duration of activity and the mean amplitude of the slow waves. This figure approximates to that which would be obtained by integrating the area under the trace with a planimeter or by electronic integration (Fig. 4).

The proportion of the time of analysis in which fast waves (five per minute or more) occurred has been recorded.

TABLE I

COMPARISON OF ONE HALF HOUR AND ONE HOUR PERIODS OF ANALYSIS

\begin{tabular}{|c|c|c|c|c|c|c|}
\hline \multirow[t]{2}{*}{ Subject } & \multicolumn{3}{|c|}{ First Half Hour } & \multicolumn{3}{|l|}{ One Hour } \\
\hline & $\begin{array}{l}\text { Percentage } \\
\text { Duration of } \\
\text { Activity }\end{array}$ & $\begin{array}{l}\text { Percentage Waves } \\
>20 \mathrm{~cm} \text {. } \\
\text { Water Pressure }\end{array}$ & $\begin{array}{l}\text { Percentage Duration } \\
\text { of time in which } \\
\text { Fast Waves Occur }\end{array}$ & $\begin{array}{l}\text { Percentage } \\
\text { Duration of } \\
\text { Activity }\end{array}$ & $\begin{array}{l}\text { Percentage Waves } \\
>20 \mathrm{~cm} . \\
\text { Water Pressure }\end{array}$ & $\begin{array}{l}\text { Percentage Duration } \\
\text { of time in which } \\
\text { Fast Waves Occur }\end{array}$ \\
\hline 1 & 49 & 33 & 0 & 29 & 17 & $\mathbf{0}$ \\
\hline 2 & 47 & 40 & 2 & 52 & 50 & 1 \\
\hline 3 & 70 & 33 & 0 & 74 & 32 & 0 \\
\hline 4 & 23 & 33 & 0 & 25 & 28 & 0 \\
\hline 5 & 20 & 33 & 0 & 16 & 33 & $\mathbf{0}$ \\
\hline 6 & 48 & 12 & 3 & 61 & 16 & 2 \\
\hline 7 & 0 & 0 & 0 & 0 & $\mathbf{0}$ & o \\
\hline 8 & 30 & 10 & $\mathbf{0}$ & 39 & 8 & 0 \\
\hline 9 & 67 & 0 & $\mathbf{0}$ & 65 & 0 & $\mathbf{0}$ \\
\hline 10 & 72 & 16 & 0 & 69 & 21 & $\mathbf{0}$ \\
\hline 11 & 83 & 3 & 5 & 78 & 2 & 6 \\
\hline 12 & 50 & 2 & 20 & 57 & 1 & 25 \\
\hline 13 & 47 & 77 & 2 & 43 & 62 & 3 \\
\hline 14 & 72 & 8 & 0 & 68 & 7 & $\mathbf{0}$ \\
\hline 15 & 18 & $\mathbf{0}$ & $\mathbf{0}$ & 23 & $\mathbf{0}$ & $\mathbf{0}$ \\
\hline 16 & 73 & 21 & 0 & 60 & 19 & $\mathbf{0}$ \\
\hline 17 & 70 & 16 & 0 & 65 & 17 & $\mathbf{0}$ \\
\hline 18 & 65 & 8 & 0 & 62 & 8 & $\mathbf{0}$ \\
\hline $\begin{array}{l}\text { Mean } \\
\text { S.D. }\end{array}$ & $\begin{array}{r}=50 \cdot 2 \\
= \pm 23.0\end{array}$ & $\begin{array}{r}19.2 \\
\pm 19.1\end{array}$ & $\begin{array}{r}1.8 \\
\pm 4.6\end{array}$ & $\begin{array}{r}49.2 \\
\pm 21.8\end{array}$ & $\begin{array}{r}17.8 \\
\pm 17.2\end{array}$ & $\begin{array}{r}2.1 \\
\pm 5.8\end{array}$ \\
\hline
\end{tabular}


FIG. 3. Normal colonic activity. The lowest tracing shows only respiratory activity but activity fron the colon is present in the other two tracings. Top trace $=$ stethograph. Verticals $=1$ minute intervals. Calibration in $10 \mathrm{~cm}$. water steps.

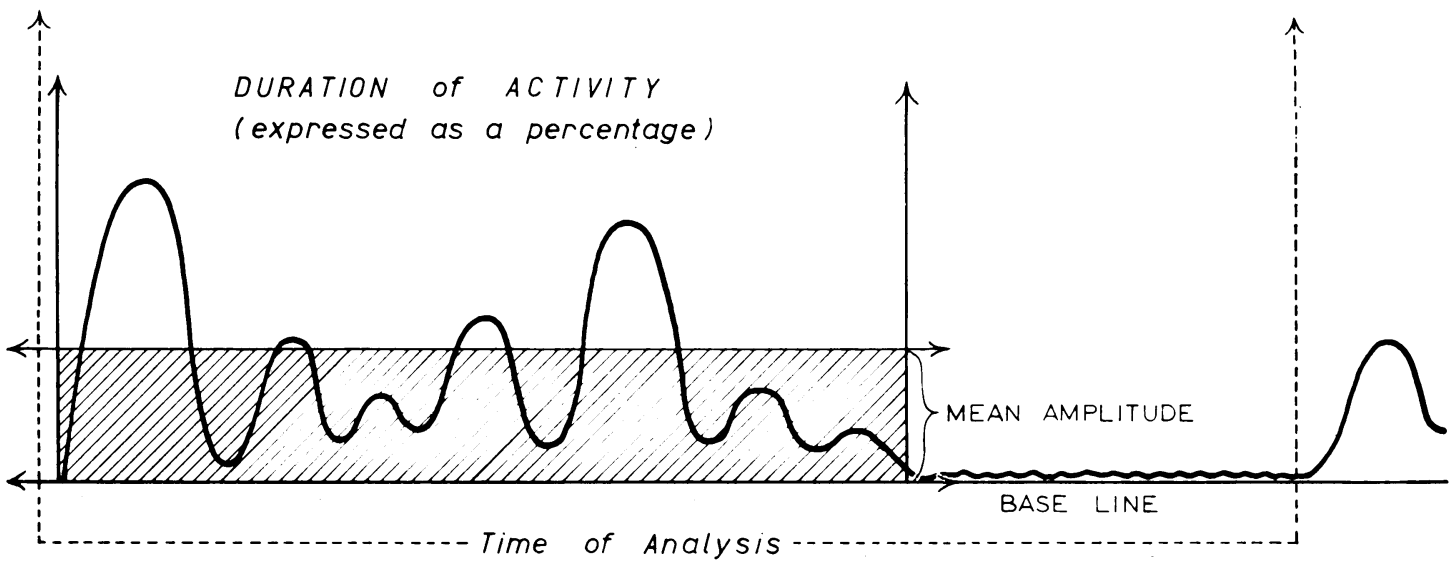

FIG. 4. Diagrammatic representation of the signif.cance of 'total activity'. Total activity = product of duration of actii $i$ y $(\%) \times$ mean amplitude.

ERROR OF ANALYSIS Analysis of complex records of the type obtained in this study involves an observer error. However, it soon became evident that this error was only significant in estimating the duration of activity. This error has been estimated by determining the duration of activity of each of six records on 10 separate occasions. The results of this analysis are set out in Table Ila. It will be seen that the variation of the results about the mean was approximately the same in the different subjects and not related to the absolute duration of activity. The mean 
TABLE II

ERROR OF ANALYSIS

TEN SEPARATE ANALYSES OVER THE SAME 30-MINUTE PERIOD IN SIX DIFFERENT RECORDS

Subject Observation

\begin{tabular}{|c|c|c|c|c|c|c|c|c|c|c|c|c|}
\hline & 1 & 2 & 3 & 4 & 5 & 6 & 7 & 8 & 9 & 10 & Mean & S.D. \\
\hline \multicolumn{13}{|c|}{ (a) Single analysis of the percentage duration of activity } \\
\hline 1 & 47 & 50 & 45 & 48 & 46 & 57 & 46 & 47 & 43 & 50 & 48 & \pm 3.9 \\
\hline 2 & 45 & 47 & 47 & 47 & 43 & 47 & 55 & 42 & 38 & 50 & 46 & $\pm 4 \cdot 6$ \\
\hline 3 & 17 & 17 & 15 & 23 & 15 & 23 & 15 & 17 & 18 & 18 & 18 & \pm 2.9 \\
\hline 4 & 20 & 23 & 15 & 20 & 17 & 20 & 20 & 18 & 13 & 15 & 18 & $\pm \mathbf{3} \cdot 0$ \\
\hline 5 & 60 & 60 & 57 & 57 & 58 & 63 & 57 & 60 & 63 & 57 & 59 & \pm 2.4 \\
\hline 6 & 52 & 50 & 55 & 48 & 53 & 53 & 53 & 50 & 52 & 50 & 52 & $\pm 2 \cdot 1$ \\
\hline
\end{tabular}

(b) Duplicate analyses of the percentage duration of activity

\begin{tabular}{|c|c|c|c|c|c|c|c|c|c|c|c|c|}
\hline 1 & 49 & 47 & 52 & 47 & 47 & 48 & 47 & 52 & 45 & 48 & 48 & $+2 \cdot 2$ \\
\hline 2 & 46 & 47 & 45 & 49 & 44 & 47 & 45 & 51 & 40 & 48 & 46 & $\pm \mathbf{3} .0$ \\
\hline 3 & 17 & 19 & 19 & 16 & 18 & 16 & 19 & 19 & 18 & 18 & 18 & \pm 1.2 \\
\hline 4 & 22 & 18 & 19 & 19 & 14 & 19 & 19 & 20 & 16 & 18 & 18 & $\pm 2 \cdot 1$ \\
\hline 5 & 60 & 57 & 61 & 59 & 60 & 59 & 58 & 60 & 62 & 59 & 60 & \pm 1.4 \\
\hline 6 & 51 & 52 & 53 & 52 & 51 & 53 & 51 & 53 & 51 & 51 & 52 & $\begin{array}{l} \pm .9 \\
\pm 0\end{array}$ \\
\hline
\end{tabular}

Mean S.D. $= \pm 1 \cdot 8$

of these standard deviations is $\pm 3 \cdot 2 \%$. This was felt to be too great an error and therefore the standard deviations of duplicate analyses were calculated (Table IIb) and the mean of these standard deviations was considerably less $(\sigma= \pm 1 \cdot 8)$. Thus with duplicate analyses it is unlikely that an error of more than $5 \%$ will occur $(P=1: 100)$ and all figures for analyses in this study refer to the mean of two duplicate analyses.

\section{RESULTS}

COMPARISON OF MOTILITY OF PATIENTS WITH DUODENAL ULCER AND OF NORMALS Table III compares the analyses of the records from patients who had a duodenal ulcer and those of the normal subjects. The groups are compared at three levels; in the sigmoid colon, at the rectosigmoid area, and in the upper rectum. There are no significant differences between the groups.

COMPARISON OF MOTILITY AT DIFFERENT SEGMENTS OF PELVIC COLON Considering all the records from all the subjects, Table IV presents the analyses from the sigmoid, the rectosigmoid region, and the upper rectum. The mean duration of activity of the upper rectum does not differ significantly from that of the rectosigmoid or sigmoid but the amplitude of the

TABLE III

COMPARISON OF COLONIC MOTILITY OF PATIENTS WITH DUODENAL ULCER AND CONTROLS

\begin{tabular}{|c|c|c|c|c|c|c|}
\hline & \multicolumn{2}{|c|}{$\begin{array}{l}\text { In Sigmoid Colon } \\
(20-25 \mathrm{~cm} .)\end{array}$} & \multicolumn{2}{|c|}{$\begin{array}{l}\text { At Rectosigmoid Area } \\
(15-20 \mathrm{~cm} .)\end{array}$} & \multicolumn{2}{|c|}{$\begin{array}{l}\text { In Upper Rectum } \\
(10-15 \mathrm{~cm} .)\end{array}$} \\
\hline & $\begin{array}{l}\text { Duodenal } \\
\text { Ulcer }\end{array}$ & Control & $\begin{array}{l}\text { Duodenal } \\
\text { Ulcer }\end{array}$ & Control & $\begin{array}{l}\text { Duodenal } \\
\text { Ulcer }\end{array}$ & Control \\
\hline Number & 14 & 18 & 10 & 16 & 8 & 15 \\
\hline $\begin{array}{l}\text { Duration of activity }(\%) \\
\text { Mean amplitude of principal waves }\left(\mathrm{cm} . \mathrm{H}_{2} \mathrm{O}\right) \\
\text { Total activity }(1 \times 2) \\
\text { Waves of } 20 \mathrm{~cm} . \text { water pressure }(\%) \\
\text { Time occupied by fast waves }(\%)\end{array}$ & $\begin{aligned} 47 \cdot 8 & \pm 21 \cdot 5 \\
12 \cdot 3 & \pm 7 \cdot 3 \\
640 & \pm 393 \\
21 \cdot 0 & \pm 21 \cdot 0 \\
0 \cdot 8 & \pm 1 \cdot 7\end{aligned}$ & $\begin{aligned} 54 \cdot 3 & \pm 24 \cdot 0 \\
10 \cdot 7 & \pm 6 \cdot 2 \\
640 & \pm 389 \\
20 \cdot 8 & \pm 17 \cdot 5 \\
2 \cdot 4 & \pm 5 \cdot 3\end{aligned}$ & $\begin{aligned} 46 \cdot 3 & \pm 23 \cdot 9 \\
11 \cdot 2 & \pm 9 \cdot 2 \\
513 & \pm 403 \\
19 \cdot 6 & \pm 21 \cdot 8 \\
2 \cdot 8 & \pm 4 \cdot 0\end{aligned}$ & $\begin{aligned} 52 \cdot 5 & \pm 22 \cdot 3 \\
12 \cdot 0 & \pm 7 \cdot 0 \\
689 & \pm 520 \\
19 \cdot 5 & \pm 16 \cdot 9 \\
5 \cdot 3 & \pm 7 \cdot 4\end{aligned}$ & $\begin{aligned} 52 \cdot 6 & \pm 26 \cdot 6 \\
7 \cdot 3 & \pm 4 \cdot 5 \\
456 & \pm 432 \\
13 \cdot 4 & \pm 16 \cdot 1 \\
3 \cdot 5 & \pm 4 \cdot 5\end{aligned}$ & $\begin{array}{r}64 \cdot 6 \pm 27 \cdot 2 \\
7 \cdot 0 \pm 4 \cdot 5 \\
501 \pm 415 \\
9 \cdot 2 \pm 12 \cdot 4 \\
5 \cdot 9 \pm 14 \cdot 1\end{array}$ \\
\hline
\end{tabular}

TABLE IV

COMPARISON OF MOTILITY OF SIGMOID, RECTOSIGMOID, AND UPPER RECTUM IN ALL SUBJECTS

\begin{tabular}{|c|c|c|c|}
\hline & Sigmoid & Rectosigmoid & Upper Rectum \\
\hline Number & 32 & 26 & 23 \\
\hline $\begin{array}{l}\text { Duration of activity }(\%) \\
\text { Mean amplitude of principal waves }\left(\mathrm{cm} . \mathrm{H}_{2} \mathrm{O}\right) \\
\text { Total activity }(=1 \times 2) \\
\text { Waves of } 20 \mathrm{~cm} \text {. water pressure }(\%) \\
\text { Time occupied by fast waves }(\%) \\
\text { Frequency (waves } / \text { min.) }\end{array}$ & $\begin{aligned} 51 \cdot 4 & \pm 22 \cdot 3 \\
11 \cdot 5 & \pm 6 \cdot 5 \\
640 & \pm 378 \\
20 \cdot 9 & \pm 18 \cdot 5 \\
1 \cdot 7 & \pm 4 \cdot 1 \\
2 \cdot 2 & \end{aligned}$ & $\begin{aligned} 50 \cdot 2 & \pm 22 \cdot 5 \\
11 \cdot 7 & \pm 7 \cdot 7 \\
619 & \pm 467 \\
19 \cdot 5 & \pm 18 \cdot 3 \\
4 \cdot 4 & \pm 6 \cdot 2 \\
- & \end{aligned}$ & $\begin{aligned} 60 \cdot 7 & \pm 26 \cdot 5 \\
7 \cdot 1 & \pm 4 \cdot 5 \\
485 & \pm 410 \\
10 \cdot 7 & \pm 13 \cdot 6 \\
5 \cdot 0 & \pm 11 \cdot 5 \\
2 \cdot 6 & \end{aligned}$ \\
\hline
\end{tabular}


contractions in the rectum is significantly reduced. The frequency of the waves increases in the more caudal segments and the proportion of time occupied by waves of five per minute or more is also greater. These differences support the view that there is a functional distinction between the sigmoid and upper rectum.

DAY-TO-DAY VARIATION In one patient in whom studies were done on five occasions under the same conditions, the records obtained varied widely. The duration of activity varied between 10 and $90 \%$. There was, however, close similarity in the features of the records during the active phases on each occasion. There was no obvious alteration in this patient's emotional reactions on the different occasions of study.

On the other hand, a second patient was studied on four occasions and produced very similar recordings on each occasion. The surprising feature in this patient was that the emotional state varied widely on different occasions of recording. On two occasions she was deeply disturbed emotionally and on one of these wept freely due to the discussion of distressing life experiences, while on the other two occasions she was resting quietly, without any evidence of emotional disturbance and slept for a time. The analysis of the two records obtained while the patient was under emotional stress is compared with the two records obtained while she was calm (Table V).
TABLE V

EFFECT OF MOOD ON COLONIC MOTILITY OF ONE SUBJECT

$\begin{array}{ll}\begin{array}{l}\text { Emotionally } \\ \text { Disturbed }\end{array} & \begin{array}{l}\text { Emotionally } \\ \text { Calm }\end{array} \\ \text { (Mean of Two } & \text { (Mean of Two } \\ \text { Experiments) } & \text { Experiments) }\end{array}$

Duration of activity $(\%)$

Experiments)

94

Mean amplitude of principal

waves $\left(\mathrm{cm} . \mathrm{H}_{2} \mathrm{O}\right)$

Total activity

Waves of $20 \mathrm{~cm}$. water pressure $(\%)$

Time occupied by fast waves

$\begin{array}{cc}24 \cdot 4 & 20 \cdot 2 \\ 2,095 & 1,899 \\ 51 & 43 \\ 2 & 4\end{array}$

Records were also analysed qualitatively.

PRINCIPAL WAVES The same features are seen in records from patients with duodenal ulcers and from normal subjects. A typical record is illustrated in Fig. 5. The principal wave represents a slow pressure change waxing and waning over approximately half a minute. The amplitude of these waves varies from less than 5 to more than $100 \mathrm{~cm}$. of water pressure. Their distribution is irregular. Frequently, they occur in phases of activity which alternate with phases of relative inactivity. The duration and proportion of the active and inactive periods vary widely from subject to subject and in the same subject from time to time. Usually, however, the periodicity of these cycles is less than half an hour, although periods of total quiescence of up to one and a half hours, have been observed. Where the waves occur in

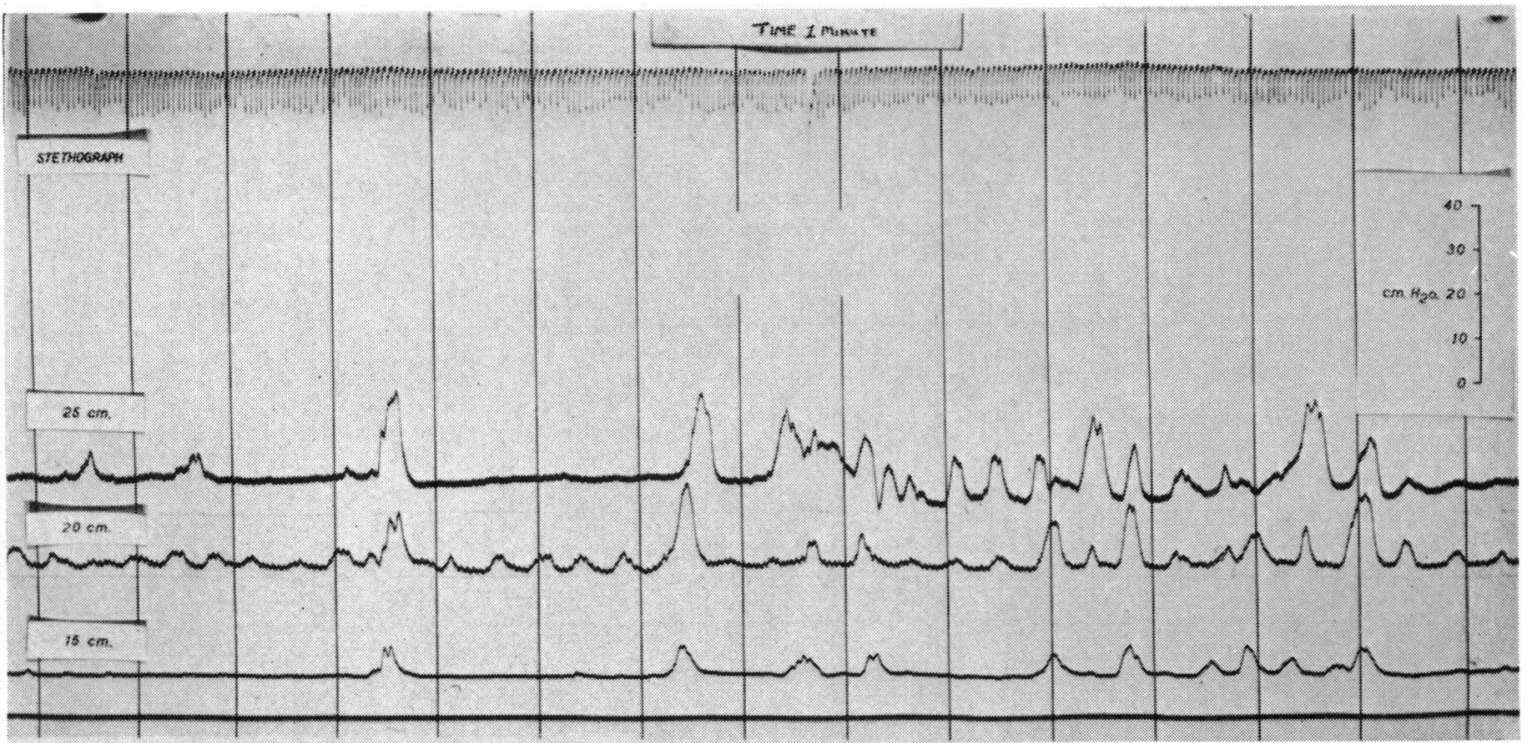

FIG. 5. Normal colonic activity: principal waves. Top tracing $=$ stethograph. Verticals $=1$ minute intervals. Calibration in $10 \mathrm{~cm}$. water steps. 


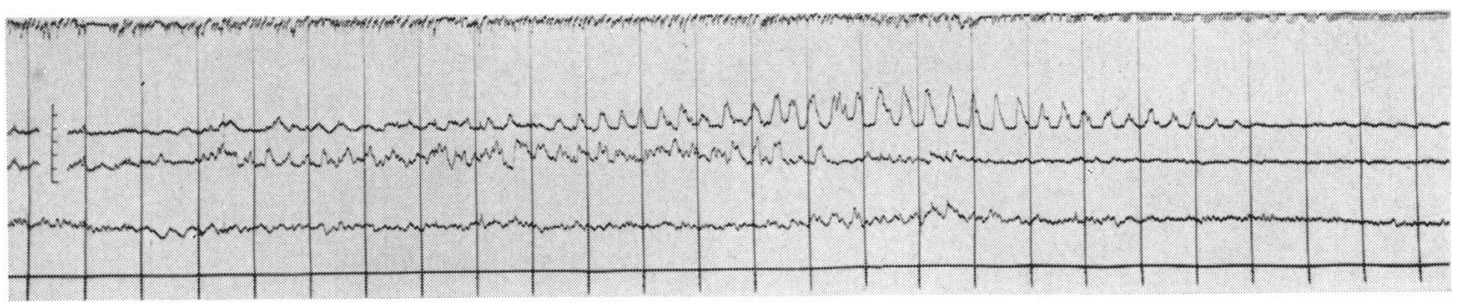

FIG. 6. Normal colonic activity: gradual increase in amplitude of principal waves during phasic activity. Top trace = stethograph. Verticals $=1$ minute intervals. Calibration in $10 \mathrm{~cm}$. water steps.

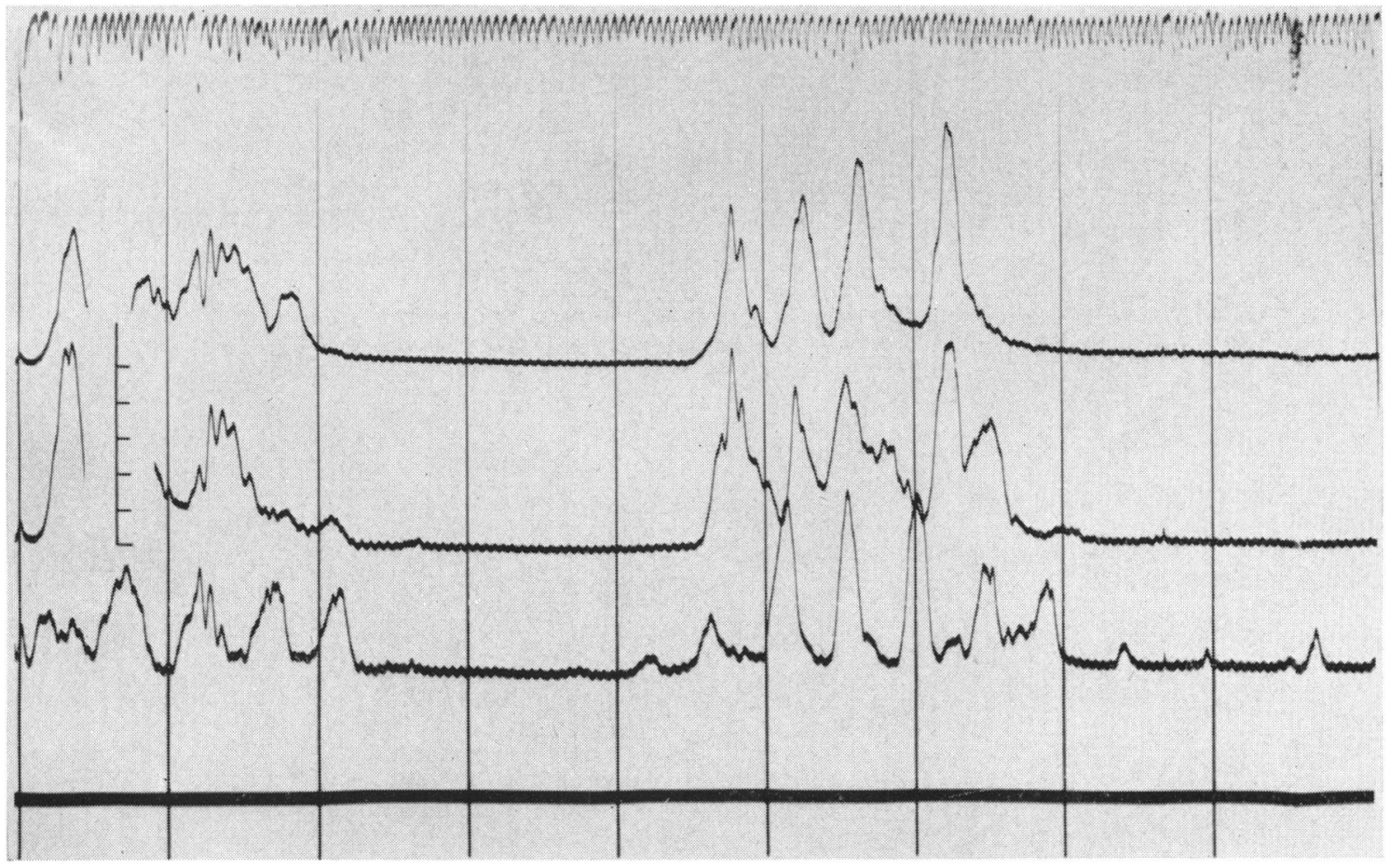

FIG. 7. Normal colonic activity: short periods of high amplitude principal waves. Top tracing $=$ stethograph. Vertical $=1$ minute intervals. Calibration in $10 \mathrm{~cm}$. water steps.

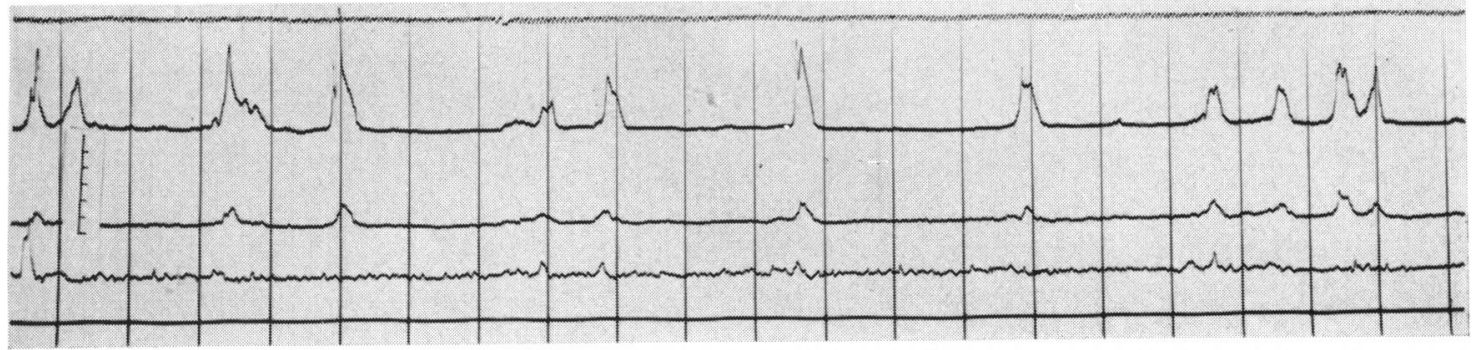

FIG. 8. Normal colonic activity: solitary principal waves. Top tracing $=$ stethograph. Verticals $=1$ minute intervals. Calibration in $10 \mathrm{~cm}$. water steps. 


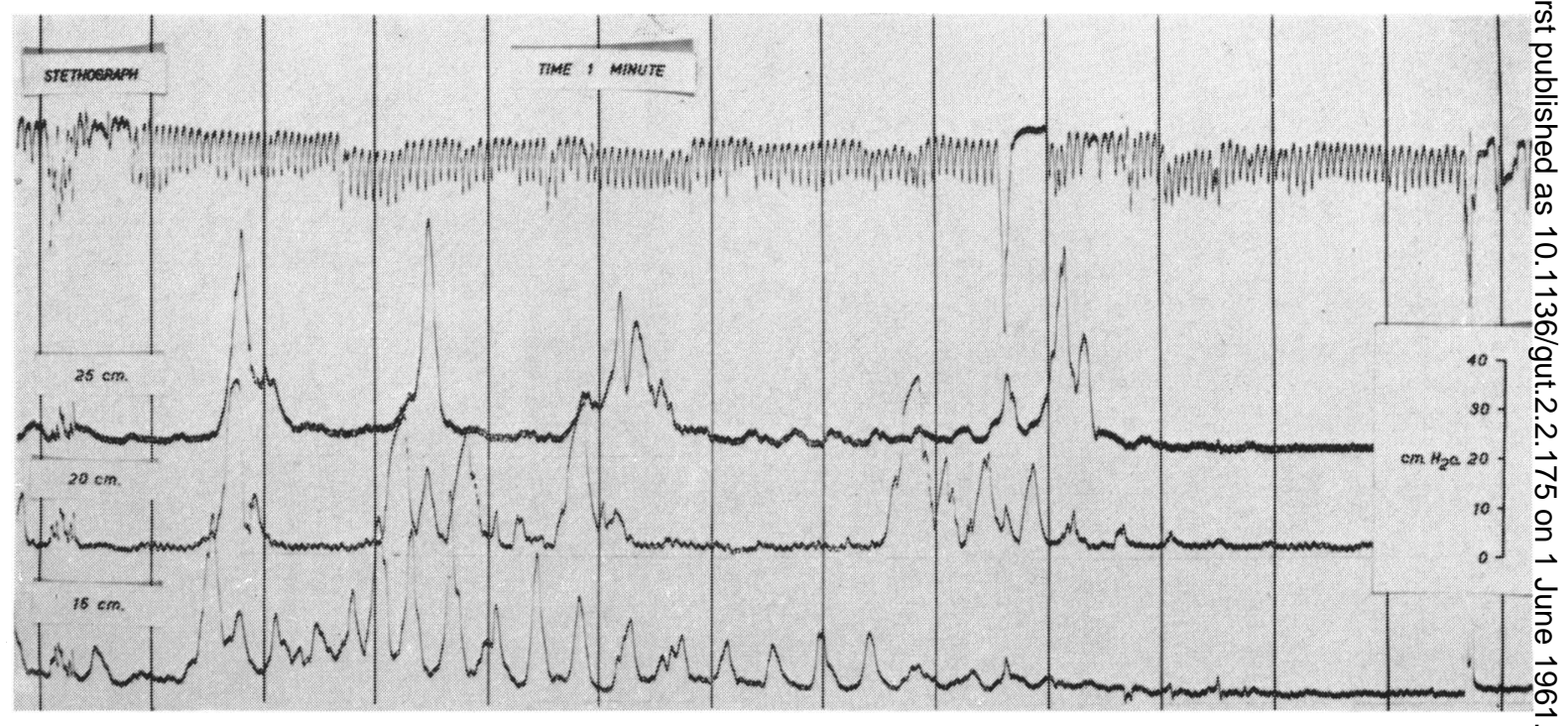

FIG. 9. Normal colonic activity: independent segmental activity in simultaneous recording from points separated by $5 \mathrm{~cm}$. Top tracing $=$ stethograph. Verticals $=1$ minute intervals. Calibration in $10 \mathrm{~cm}$. water steps.

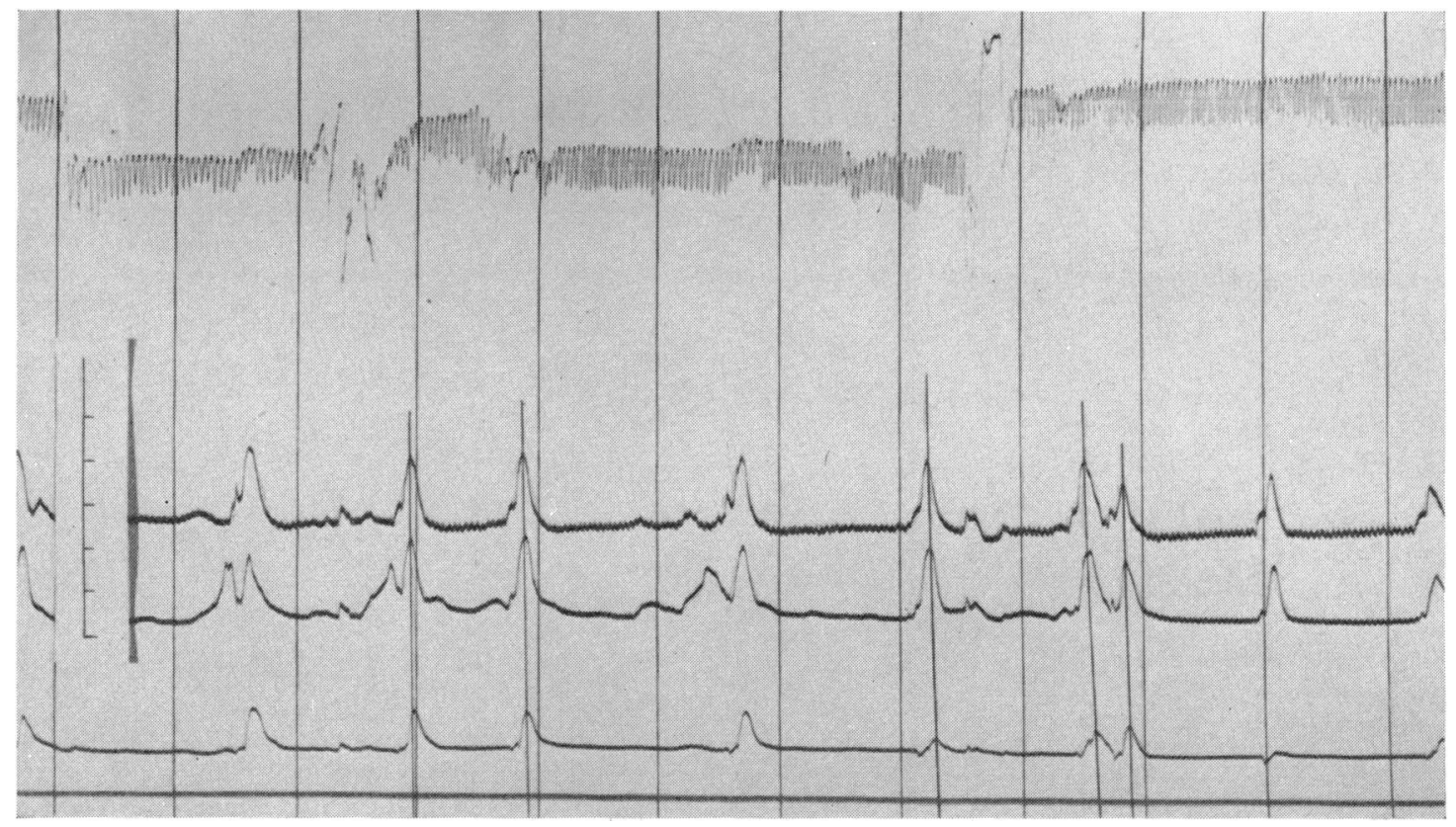

FIG. 10. Normal colonic activity: progressive waves (lines have been drawn through waves which represent forward peristalsis). Top tracing $=$ stethograph. Verticals $=1$ minute intervals. Calibration in $10 \mathrm{~cm}$. water steps. 


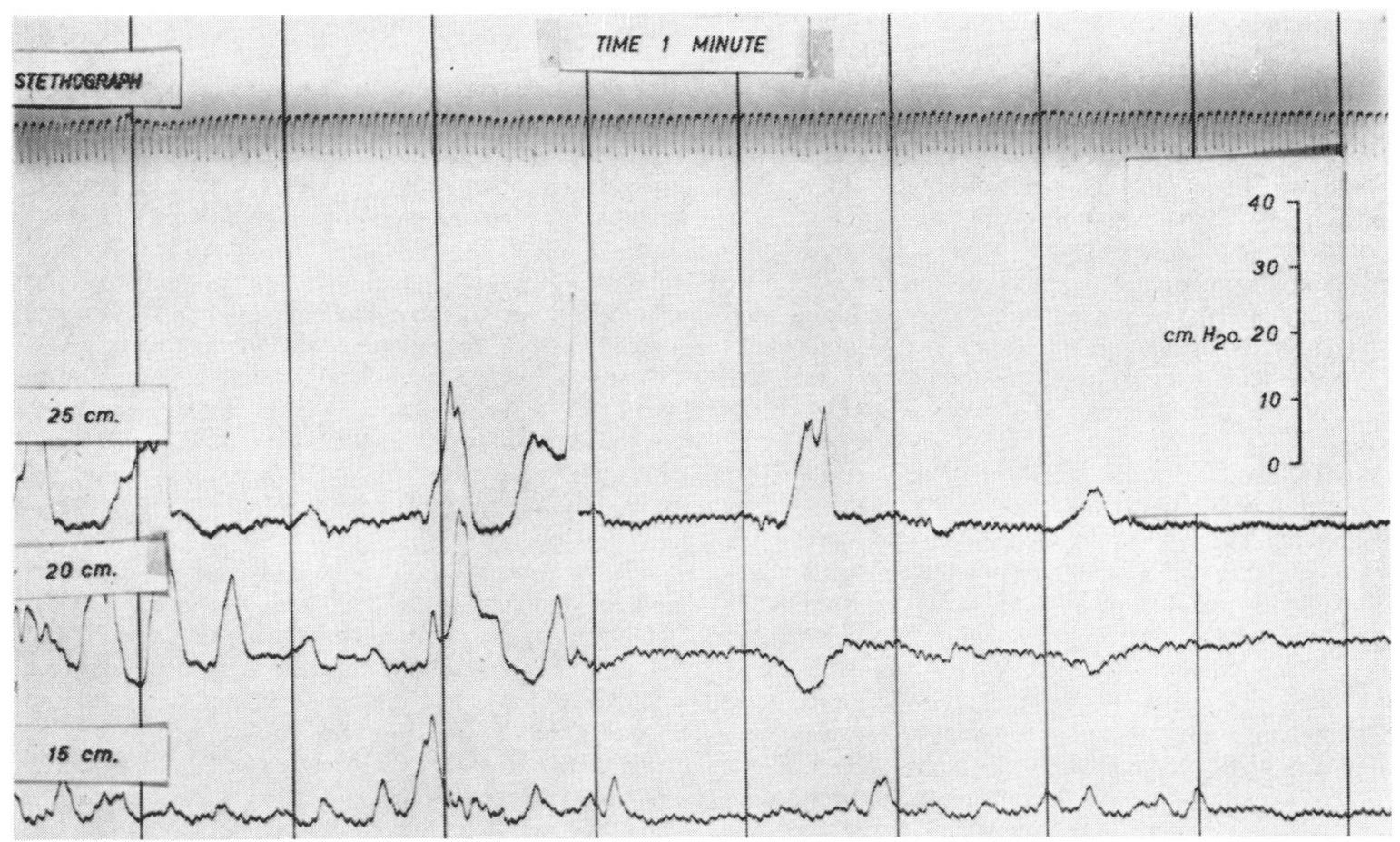

FIG. 11. Normal colonic activity: relaxation (middle colonic tracing) associated with proximal contraction (upper colonic tracing). Top tracing $=$ stethograph. Verticals $=1$ minute intervals. Calibration in $10 \mathrm{~cm}$. water steps.

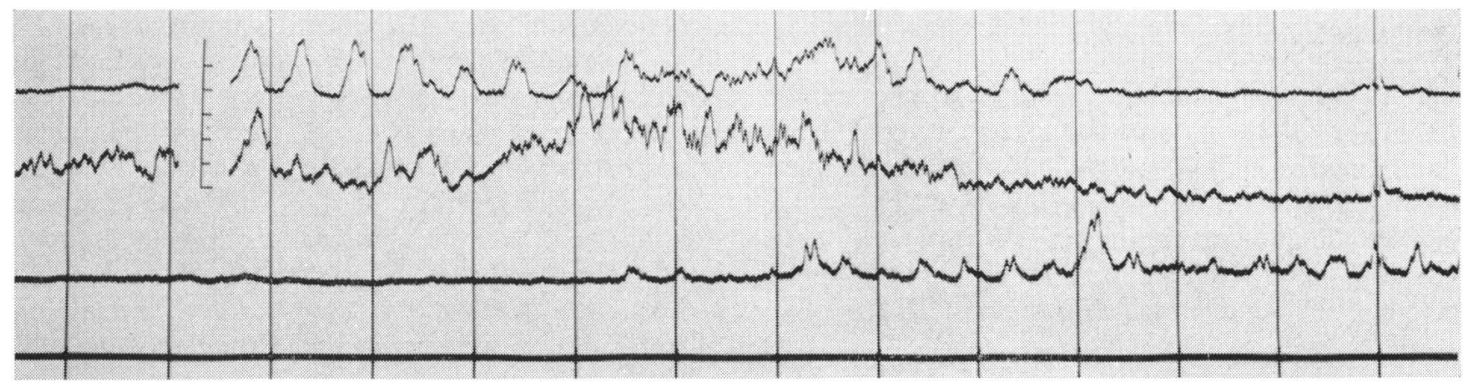

FIG. 12. Normal colonic activity: rise in base line with superimposed colonic waves. Verticals $=1$ minute intervals. Calibration in $10 \mathrm{~cm}$. water steps.

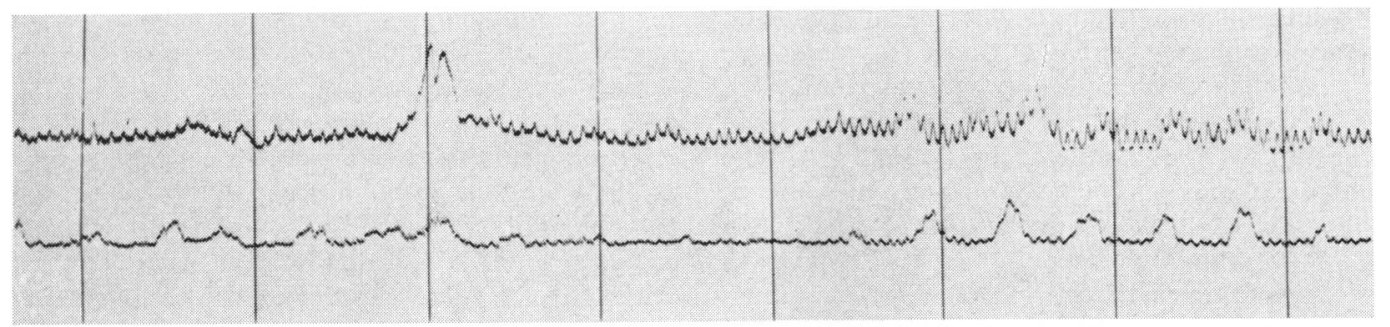

FIG. 13. Normal colonic activity: alteration in amplitude of respiratory swing (upper tracing). Verticals $=1$ minute intervals. Calibration in $10 \mathrm{~cm}$. water steps. 
rhythmic sequence there is often a gradual buildup of amplitude followed by a gradual decline (Fig. 6). At other times, however, a short burst of waves of high amplitude may occur without any previous build-up (Fig. 7). Again independent solitary waves are not at all infrequent (Fig. 8, top trace). While the amplitude of these waves varies widely their frequency is remarkably constant at any given position in the pelvic colon, and when they occur in rhythmic sequence they seldom vary beyond the range of 1.8 to 2.7 per minute. They appear to correspond in form to the type described as type II (Templeton and Lawson, 1931).

SEGMENTAL ACTIVITY Simultaneous records from points separated by only short distances are frequently dissimilar, indicating independent segmental activity (Fig. 9). Whether or not the principal waves result in propulsion of the bowel contents will depend largely on the relationship of the pressures in neighbouring segments. Waves which are conducted over three segments are only rarely seen. One period in which such peristaltic waves were seen is illustrated in Fig. 10. This, however, was the only period in which such integrated progressive activity was seen in a record lasting five hours. The rate of progression in this case was $2.5 \mathrm{~cm}$. per second. Waves representing reverse peristalsis at approximately the same rate also occur infrequently. Rarely distal relaxation associated with proximal contraction can be seen (Fig. 11).

FAST WAVES In the rectum there is an appreciable proportion of waves whose frequency varies from 5 to 10 cycles per minute. The amplitude of these fast waves is nearly always less than $20 \mathrm{~cm}$. water pressure. They are very much less frequently seen in the sigmoid. They correspond to the type I described by Templeton and Lawson (1931).

CHANGES IN BASE LINE In some records there is a slow rise and fall of base line, the total duration of which may be 30 minutes or more, and the maximal amplitude is usually less than $5 \mathrm{~cm}$. of water pressure. Base line changes of shorter duration also occur and frequently represent greater pressures, and are always associated with superimposed waves (Fig. 12). These changes in base line probably have some relationship to bowel 'tone'. The amplitude of the respiratory swings may also be a crude measure of tone because it varies considerably (Fig. 13, top trace). It presumably depends on the degree to which intra-abdominal pressure changes are transmitted into the lumen of the gut which in turn may be related inversely to the rigidity or tone of the bowel wall.
DISCUSSION

The pressures recorded in this study are the intraluminal pressures developed in the colon under resting physiological conditions. It is generally agreed that open tubes provide a true measure of intraluminal pressures (Quigley and Brody, 1950), and we have shown that open-ended tubes and miniature balloons give essentially similar results over the range of pressures generated in the colon. Indeed, in our experience, balloons are to be preferred to open-ended tubes for recording colonic motility if a 'tube' system is being employed. Even for the study of narrow segments such as the cardiac and pyloric sphincters balloons have been found to have certain advantages by Atkinson et al. (1957) and by Code and Schlegel (1958).

The analysis of motility records remains difficult and unstandardized. As Davidson et al. (1956) pointed out, the analysis into waves of Types I, II, III, and IV is an over-simplification, since all possible variations in duration and amplitude of waves occur. For example, Type III waves are defined as a rise in base line on which waves of Type I or II or both are superimposed (Adler et al., 1941). However, the base line will rise when the rhythmic activity is sufficiently rapid or so powerful that the pressure generated by one contraction is not completely dissipated before the succeeding one begins. That is, this complex represents tetanic summation of a series of contractions. It seems therefore unrealistic to designate this feature as a distinct wave form. In addition, in some of the early papers, where sluggish water manometers were used, some of the forms described as Type III waves may have been the result of the sluggish response of the instrument resulting in a failure of the writing point to return to the base line before the start of another contraction.

On account of the very slow rate of contraction of the colon it appears to be a relatively inactive organ on radiological screening. This study, however, reveals activity of the colon for slightly more than half the time of recording under resting conditions. In this, our results agree with those of previous workers. Adler et al (1941) found activity for more than $50 \%$ of the time in the descending colon and Spriggs et al. (1951) found activity for $36 \%$ of the time in the pelvic colon of fasting subjects. It is interesting that there is agreement with these workers as they used large stimulating balloons to record colonic motility. Our results also agree with other workers using open-ended tubes. Davidson et al. (1956) found activity for $44 \%$ of the time in the sigmoid colon of children and Fink and Friedman (1960) showed that the range of activity was from 15 to $60 \%$ in the ascending colon in man. 
In our records the greatest proportion of the time of activity is occupied by principal waves which do not appear to be progressive but to occur in an independent segmental manner. A contraction causing a high pressure in one segment associated with a lower pressure in a neighbouring segment will tend to propel the content of the bowel in the direction of this pressure gradient. If, however, the gradient reverses, the tendency will be for the contents to move in the opposite direction. Hence, the effect of these principal waves is to move the bowel content to and fro over a short length of bowel without any definite progression analwards. Barclay (1935) has shown that the rhythmic haustral contractions of the colon similarly move the contents from side to side and backwards and forwards over short distances, and Code, Hightower, and Morlock (1952) believe that the haustral contractions are the radiological analogue of the principal waves.

It is a well-known fact that sigmoidoscopically the greater bulk of faeces is usually found not in the rectum but at the rectosigmoid junction and above. Some mechanism must exist which prevents the forward progression of faeces. It has been shown that a high pressure zone does not exist at the rectosigmoid (Hill, Kelley, Schlegel, and Code, 1960). The finding that waves at a higher frequency were present for a longer proportion of the time in the upper rectum than in the sigmoid colon may be important because they might have the effect of protecting the rectum from overfilling. Spriggs et al. (1951) also found that $17 \%$ of the time of activity in the lower rectum was occupied by Type 1 or fast activity as opposed to $1 \%$ in the sigmoid. I have examined only a small number of records from the lower rectum but these few observations confirm the prominence of fast waves in this area. This increasing frequency of waves from sigmoid to anus may be a physiological mechanism whereby constant forward propulsion of faeces on to the sensitive areas for the final defaecation reflex in the lower rectum (Goligher and Hughes, 1951) is prevented.

The day-to-day variation of colonic motility in the same subject may be very considerable although the variation over several hours in the same day is much less marked. For this reason comparative studies of colonic activity in records obtained on different days must be interpreted with caution. The role of emotion in producing these day-to-day variations is problematical.

The pattern of colonic motility that emerges from this study confirms the experience of previous authors using large balloons and indicates an organ which is relatively active with approximately equal periods of activity and inactivity, the usual length of a complete cycle being about 30 minutes. In this it differs from the stomach where long periods of inactivity are broken only by short periods of rhythmic contraction, and from the small intestine in that the rate of contraction is very much slower.

The failure to demonstrate any difference in bowel motility between normals and patients with duodenal ulceration is at first sight surprising, but it should be emphasized again that our patients had no symptoms at the time of study. There is little evidence that the motility of the gastrointestinal tract is altered by the presence of a duodenal ulcer. Claims have been made that there is hypermotility of the stomach (Anderson, 1943) but Foulk, Code, Morlock, and Bargen (1954) and Smith, Texter, Stickley, and Barborka (1957) found no significant difference in small bowel motility between normals and patients with asymptomatic duodenal ulceration. The latter authors, however, did find significant changes in patients with active ulceration when pain was present. This present study shows no difference in the colonic motility in patients with asymptomatic duodenal ulceration but the presence of pain might affect colonic motility. Further work is required to establish this.

\section{SUMMARY}

The unstimulated motility of the sigmoid colon has been studied under physiological conditions using miniature balloons, which are advocated as the method of choice in studying this area of the bowel.

Normal patterns of colonic motility have been established and an analysis of the salient features of the motility records is presented.

On average the colon of normal subjects is active for $50 \%$ of the time of recording, but there is a wide range of activity in different persons and even in the same person from day to day.

The principal wave of the colon represents a slow independent segmental contraction lasting approximately one half minute, which does not have primarily a propulsive function.

There are differences in the frequency of contractions and the amplitude of the waves between the sigmoid colon and the rectum. The possible physiological significance is discussed.

Waves representing either forward peristalsis or reverse peristalsis are only occasionally seen.

There is no difference in the colonic motility of normal subjects and patients with asymptomatic duodenal ulceration.

I want to thank Dr. F. Avery Jones, Dr. T. D. Kellock, and the surgeons of St. Mark's Hospital for permission to study their patients. 
The work was done while supported by a grant from the Medical Research Council held jointly by Dr. E. N. Rowlands and Mr. I. P. Todd, to whom I am indebted for helpful encouragement and advice at all stages in this work.

\section{REFERENCES}

Adler, H. F., Atkinson, A. J., and Ivy, A. C. (1941). A study of the motility of the human colon: An explanation of dysynergia of the colon, or of the "unstable colon". Amer. J. dig. Dis., $8,197-202$.

Anderson, W. F. (1943). Motility of the fasting stomach in health and disease. Lancet, 1, 40-42.

Atkinson, M., Edwards, D. A. W., Honour, A. J., and Rowlands, E. N. (1957). Comparison of cardiac and pyloric sphincters: A manometric study. Ibid, 2, 918-922.

Barclay, A. E. (1935). Direct $x$-ray cinematography, with a preliminary note on the nature of the non-propulsive movements of the large intestine. Brit. J. Radiol., 8, 652-658.

Bockus, H. L. (1944). Gastro-enterology, Vol. II, p. 497. Saunders, Philadelphia.

Code, C. F., Hightower, N. C., Jr., and Morlock, C. G. (1952). Motility of the alimentary canal in man. Amer. J. Med., 13, 328-351.

-, and Schlegel, J. F. (1958). The pressure profile of the gastroesophageal sphincter in man: An improved method of detection. Proc. Mayo Clin., 33, 406-414.

Connell, A. M., and Rowlands, E. N. (1960). Wireless telemetering from the digestive tract. Gut, 1, 266-272.

Davidson, M., Sleisenger, M. H., Almy, T. P., and Levine, S. Z. (1956). Studies of distal colonic motility in children: Nonpropulsive patterns in normal children. Pediatrics, 17, 807-819.

Edwards, D. A. W., and Rowlands, E. N. (1960). An air-filled metal capsule optical manometer system. In Medical Electronics, ed. C. N. Smyth, pp. 307-312. Iliffe, London. Proc. 2nd International Conference on Medical Electronics, Paris 1959.

Fink, S., and Friedman, G. (1960). The differential effect of drugs on the proximal and distal colon. Amer. J. Med., 28, 534-450.

Foulk, W. T., Code, C. F., Morlock, C. G., and Bargen, J. A. (1954). A study of the motility patterns and the basic rhythm in the duodenum and upper part of the jejunum of human beings. Gastroenterology, 26, 601-611.

Goligher, J. C., and Hughes, E. S. R. (1951). Sensibility of the rectum and colon; its role in the mechanism of anal continence. Lancet, 1, 543-548.

Hill, J. R., Kelley, M. L., Schlegel, J. F., and Code, C. F. (1960). Pressure profile of the rectum and anus of healthy persons. Dis. Colon Rect., 3, 203-209.

Jones, F. A., and Gummer, J. W. P. (1960). Clinical Gastroenterology, p. 333. Blackwell Scientific Publications, Oxford.

Quigley, J. P., and Brody, D. A. (1950). "Digestive Tract: Intralumen pressures: Gastrointestinal propulsion, gastric evacuation, pressure-wall tension relationships." In Glasser, O., Medical Physics, Vol. 2., p. 280. The Year Book Publishers, Chicago.

Rowlands, E. N., Honour, A. J., Edwards, D. A. W., and Corbett, B. D. (1953). Metal-capsule optical manometer for measuring pressure in the human gut with an open-ended tube. Clin. Sci., 12, 299-306.

Smith, H. W., Texter, E. C., Jr., Stickley, J. H., and Barborka, C. J. (1957). Intraluminal pressures from the upper gastrointestinal tract. II. Correlations with gastroduodenal motor activity in normal subjects and patients with ulcer distress. Gastroenterology, 32, 1025-1049.

Spriggs, E. A., Code, C. F., Bargen, J. A., Curtiss, R. K., and Hightower, N. C. (1951). Motility of the pelvic colon and rectum of normal persons and patients with ulcerative colitis. Ibid, 19, 480-491.

Templeton, R. D., and Lawson, H. (1931). Studies in the motor activity of the large intestine: Normal motility in the dog, recorded by the tandem balloon method. Amer. J. Physiol., 96, 667-676.

\section{Potassium replacement therapy}

G. N. CHANDLER, C. HETHERINGTON, A. N. STEPHENSON AND M. ATKINSON From Pinderfields Hospital, Wakefield, and St. James's Hospital, Leeds

SYNOPSIS Potassium replacement is often an important therapeutic measure, and the advantages of effervescing potassium-containing granules are put forward in this article.

Potassium depletion is a very real additional danger to patients already ill from other causes. Potassium ion may be rapidly lost from the alimentary tract, as in vomiting and diarrhoea, or from the kidney when diuretics are used in diseases associated with hyperaldosteronism such as chronic liver disease or congestive cardiac failure.

The treatment of potassium depletion holds particular difficulties. When given in tablet form absorption is capricious because of the varied times taken for the tablets to disintegrate, and when intestinal transit is rapid the tablets not infrequently appear unaltered in the faeces or ileostomy bag. The bitter taste of potassiumcontaining mixtures makes them unpalatable to many patients and may lead to anorexia, nausea, and vomiting. These side-effects are particularly incommoding in conditions where the clinician aims to stimulate or at least maintain the appetite to combat malnutrition. The following prescription taken in an equal quantity of Ribena syrup is more palatable than most:

Pot. chloride.............. $1 \mathrm{~g}$.

Syrup of raspberry.......... $2 \mathrm{ml}$.

Chloroform water........... to $15 \mathrm{ml}$.

Nevertheless its use is not without the risk of gastrointestinal disturbance.

At the Royal Free Hospital an effervescent potassium tablet has been developed (Hadgraft, 1960) which is both palatable and effective. This is composed of potassium bicarbonate, potassium acid tartrate, and anhydrous citric acid. It contains $6.5 \mathrm{mEq}$. of potassium per tablet. One practical drawback has been the slowness of these tablets to go into solution and their liability to leave behind undissolved residues in the glass. Examination of the glass revealed up to $0.3 \mathrm{mEq} . \mathrm{K}$ remaining after tablets had been given to patients routinely by the nursing staff.

We prefer to use effervescent potassium-containing granules for this reason and also because their superior effervescence makes the granules rather more palatable. The formula used is:

Potassium bicarbonate........50 g.

Potassium acid tartrate........30 g.

Citric acid.................10 g.

Sodium saccharin .......... 0.5 g.

Sucrose powder...........20 g.

The granules, made by the method described in the British Pharmaceutical Codex, 1934, are dispensed either 